\title{
Arte, Crítica e Crítica como Arte Acerca do Conceito de Crítica em F. Schlegel e Novalis*
}

\author{
Márcio Seligmann-Silva**
}

Resumo: Este artigo procura desenvolver o conceito de "crítica" no primeiro romantismo, sobretudo em seus principais representantes, Friedrich Schlegel e Novalis. A partir destes autores já não se pode falar de uma obra de arte desvinculada da reflexão sobre ela, mas, por sua vez, a própria "crítica" deve se tornar arte.

Palavras-chave: romantismo alemão - crítica - arte - idealismo alemão.

Se hoje nós podemos atribuir aos românticos "a inauguração do projeto teórico na literatura” (Lacoue-Labarthe/Nancy 12), ou chamar Friedrich Schlegel de "criador da hermenêutica" (Wellek 26), é porque a crítica foi o exercício intelectual central destes autores. O trabalho incessante de leitura e crítica do texto do mundo encontrou na poesia um de seus objetos privilegiados. F.

* Este ensaio é parte da minha dissertação de mestrado Ler o Livro do Mundo: Walter Benjamin - Romantismo e Crítica Poética (pp. 92-113), defendida no departamento de Letras Modernas (Área: Língua e Literatura Alemã) da FFLCH-USP em agosto de 1991. Nesse trabalho procurei reconstruir o conceito benjaminiano de crítica do ponto de vista da sua relação com as obras de F. Schlegel e Novalis. Não se trata tanto de um estudo de influências, mas sim de uma análise de uma determinada tradição à qual filiam-se esses autores. A minha análise baseia-se numa exposição tripartida das suas obras: da sua filosofia da linguagem, da sua teoria do conhecimento e da sua teoria da crítica de arte. Aqui apresentamos o item que trata da noção romântica (e aqui esta palavra refere-se sempre às obras de F. Schlegel e Novalis) de crítica de arte.

** Mestre em Literatura Alemã pelo Departamento de Letras Modernas da FFLCH-USP e doutorando na Universidade Livre de Berlim. 
Schlegel, deste modo, tornou-se o responsável pela transposição do método do criticismo para a estética (Szondi 24).

A divisão dos gêneros literários baseou-se, de Horácio a Lessing, numa constante valorização da tipologia platônica das formas e, sobretudo, da de Aristóteles - e foi esta moldura que forneceu quase sempre as regras para o julgamento das obras. Foi através da valorização das obras de autores como Sterne, Cervantes, Shakespeare, Tasso, Ariosto, Dante, Calderón - para citar apenas alguns dos nomes principais - somado ao choque nas convenções provocado pelo drama burguês, das bürgerliche Trauerspiel $l^{(1)}$, que no século XVIII deu-se o abalo decisivo na tradição da poética clássica. Caiu então por terra a relação modelo-imitação que caracterizava a ligação entre o passado "clássico" e o presente. Dentro desse mesmo movimento de inflexão do pensamento ocidental, no nível da filosofia da história, passa-se a perceber o caráter próprio de cada época da história; cada período é encarado como uma mônada e a transposição de conceitos do passado para o presente passa a ser vista como obra praticamente impossível. Como Hans Eichner notou: "No contato com Shakespeare, Herder apontou quão absurdo era esperar-se, de um inglês do século XVII ou de um contemporâneo na Alemanha, o mesmo tipo de drama do que de um grego do séc. V a.C., e preparou, deste modo, um brusco final para o sistema de regras (Eichner 5, p. 19; Gadamer 8, p. 166; Hoffmeister 10 , p. 102). O relativismo histórico marcou profundamente a concepção romântica do mundo: cada obra agora passou a ser vista como marcada pela época e local de nascimento, como única. Isto significou, no entanto, o fim de todos os parâmetros de avaliação (Rosenfeld 17, p. 66). Eichner, continuando a sua reflexão, afirma: "Com Herder o poeta então foi presenteado nada menos do que com a liberdade criativa. Mas o que serviu para presentear o poeta com a liberdade, retirou do julgador de obras poéticas o seu instrumento herdado; 0 crítico, o resenhista, o cientista da literatura em geral encontram-se numa situação de penúria, na qual, de resto, eles ainda se encontram. O resenhista deve decidir sobre o valor ou não-valor da obra poética: esta é a sua profissão. (...) Mas como se mede o valor de algo quando não se têm leis a partir das quais se possa medir tal valor?" (Eichner 5, p. 19) A interpretação perdeu então o solo que the garantia uma objetividade universal. 
Seligmann-Silva, M., discurso (20), 1993: 115-136

Na Crítica do Juízo, Kant, como se sabe, na medida em que, seguindo o princípio iluminista da suspensão da tradição (como "pré-juízo", Vorurteil) para a construção da autonomia da humanidade, defendeu a impossibilidade de se demonstrar a validez do belo a partir de um princípio geral, ou seja, deixou o sujeito como a única instância a priori do belo — tanto no ato da sua criação como no ato da sua recepção - , abriu espaço apenas para uma subjektive Allgemeinheit (universalidade subjetiva) ${ }^{(2)}$.

A poética da Aufklärung responde a essa nova constelação de idéias com uma atitude rígida; para preservar a sua autoridade ("objetividade") assume, diante dessa crise aberta nos parâmetros da avaliação estética, uma postura meramente classificatória. Abdicam de qualquer fundamentação teórica ou de qualquer princípio unificador ${ }^{(3)}$.

Pode-se distinguir em Friedrich Schlegel duas posturas bem diversas diante desta questão. Em torno de 1795, com os seus trabalhos Vom Wert des Studiums der Griechen und Romer e Über das Studium der Griechschen Poesie, ele estabeleceu a divisão entre a arte objetiva (representada pela arte grega, cujo único objetivo é a beleza) e a arte interessante (a moderna, serva do conhecimento). Enquanto a civilização clássica é descrita como natural, e a poesia grega teria atingido um cume nunca imitável, a moderna é, nestes textos, tida apenas como "artificial" e dominada pelo entendimento, e a sua poesia é caracterizada como sendo imperfeita. Os gregos teriam fornecido os arquétipos [Urbilder] dos gêneros puros, e o estudo das suas obras e sobretudo do modelo que a história da formação [Bildung] da literatura grega apresentou, serviria para tentar elevar a poesia de então ao nível da deles. Já em 1797-8 pode-se perceber uma mudança de ponto de vista. Os conceitos de poesia clássica e romântica, que ele desenvolveu então, recobrem de certa maneira os de poesia objetiva e interessante do período passado, mas a valorização que ele atribui a ambas épocas da poesia é diferente agora. Como afirmou A. Schlagdenhauffen (18, p. 20), o ano de 1798 foi não apenas o ano da fundação da revista Athenäum, mas também o do abandono, pela parte de Schlegel, da sua "Graecomanie" (4). É justamente no Athenäum que os primeiros românticos apresentaram a sua doutrina da poesia romântica. O interesse de Schlegel pela literatura contemporânea a ele iniciara-se em $1796 \mathrm{com}$ as suas características [Karakteristiken] do Waldemar de Jakobi e do Forster (Cf. Eichner, Introdução 
a Schlegel 19, p. L), e foi num crescente até a época do Athenäum onde ele publicou o seu ensaio Über Goethes Meister, obra esta que foi de importância fundamental para a sua valorização da poesia moderna, bem como para a elaboração da poética do romantismo. Em suma, tanto F. Schlegel como Novalis - que possui inúmeros fragmentos e textos sobre o Wilhelm Meister e sobre a obra de Shakespeare - assumem a principal consequêencia da famosa "Querelle des Anciens et des Modernes", a saber: a superação do modelo de arte clássica.

Schlegel partiu do princípio de que "Uma classificação é uma definição que abarca um conjunto de definiçōes" (Schlegel 19, II, p. 181) ${ }^{(5)}$, como ele escreveu no Athenäum numa crítica evidente às posturas da poética da Aufklärung. Enquanto esta se furtava a fornecer qualquer tipo de fundamentação teórica aos seus julgamentos, ocorre o oposto com Schlegel, que em 1797 anotou: "Todos autênticos juízos [Urtheile] estéticos são, conforme a sua natureza, decretos e não podem ser outra coisa. Não se pode prová-los $[B e$ weisen], mas se deve legitimá-los" (Schlegel 20, 71). Esta legitimação, Schlegel e Novalis a basearam nas suas filosofias da arte. Um princípio fundamental desta filosofia é o papel da arte e do artista como mediuns de "Deus", ou, se se preferir, do "Absoluto". "A poesia é a base da sociedade"; "O artista é completamente transcendental"; "Poesia é grande arte da construção de uma saúde transcendental. O poeta é portanto o médico transcendental. [...] A poesia [...] mistura tudo para o seu fim dos fins - a elevação da humanidade sobre si mesma", afirmou Novalis em 1798 (14,II,pp.323 e segs.). E Schlegel, em 1800/1: "Toda obra de arte é uma alusão ao infinito" (Schlegel 19, XVIII, p. 416). Já desde 1796, ele vinculava intimamente as suas reflexões estéticas a um trabalho filosófico: "A crítica estética e o conhecimento da antigüidade deveriam decerto ser a verdadeira propedêutica da filosofia crítica" (id., ibidem, p. 15). Nesses autores, ocorre não apenas uma ligação entre o poeta e o filósofo, como também - na linha do Banquete de Platão - uma conexão entre o belo e a verdade: "Verdade e beleza são os fins objetivos para o artista" (id., ibidem, p. 377). Assim como no âmbito da linguagem havia se formulado com os românticos uma "virada subjetivista" da noção de mimologia (Seligmann-Silva 22, pp. 48-68), na arte também ocorre algo semelhante: cada artista agora passa a ser livre na sua criação, mas, por outro lado, esta estética do 
Seligmann-Silva, M., discurso (20), 1993: 115-136

gênio afirma a possibilidade de cada artista e cada obra, individualmente, abrirem o caminho para o absoluto ${ }^{(6)}$.

Benjamin resumiu na sua tese, com as seguintes palavras, a sua concepção da crítica romântica de arte como medium-de-reflexão: "Todo conhecimento crítico de uma conformação, enquanto reflexão nela, não é outra coisa senão um grau de consciência mais elevado da mesma, gerado espontaneamente. Esta intensificação [Steigerung] da consciência na crítica é, a princípio, infinita; a crítica é, então, o medium no qual a limitação da obra singular liga-se metodicamente à infinitude da arte e, finalmente, é transportada para ela, pois a arte é, como já está claro, infinita enquanto medium-de-reflexão" (Benjamin 1, I, p. 67). Este processo de "elevação" ou "intensificação" da obra dá-se, para Schlegel e Novalis, com a exposição da auto-reflexão da obra através da crítica. A crítica revela tal reflexão através da confrontação entre a obra e o seu ideal, ou, ainda dentro da terminologia romântica, ligando o seu espírito [ "Geist"] a sua letra ["Buchstab"], o que demonstra a íntima conexão existente, para estes autores, entre a sua filosofia da arte e a sua filosofia da linguagem. "A letra de toda obra é poesia, o espírito, filosofia" (Schlegel 20, 975), afirmou Schlegel. E ainda: "Crítica é, com efeito, nada mais senão comparação do espírito e da letra de uma obra, que é tratada como infinita, como absoluto e individual" (id., ibidem, 983). Nada poderia expressar melhor esta "universalidade individual", que a obra assume para os românticos de Jena. A crítica que revela o elemento filosófico da obra - o seu espírito - tem de passar necessariamente pela crítica do seu substrato material, a letra, o que gera um trabalho de complementaridade entre o estudo do âmbito material-filológico da obra e a filosofia da arte. "A doutrina do espírito e da letra" — afirmou Schlegel - "é, entre outros aspectos, tão interessante, porque pode pôr a filosofia em contato com a fillologia" (id., 19, vol. XVIII, 179). E ainda, quanto mais distante no tempo e clássica for a obra, mais indiscernível torna-se, para Schlegel, a separação do espírito e da letra: "A poesia antiga só pode ser criticada como um todo, não individualmente, porque nela espírito e letra são idênticos" (id., 996). ${ }^{(7)}$

Assim como Novalis e Schlegel haviam descrito as traduções místicas como sendo as mais elevadas pois elas "fornecem a obra ideal" (Novalis 14, II, p. 252), o mesmo se passa na crítica: "A crítica mística é a que põe, divinatória, que determina o valor, ou as Idéias a partir das quais se critica e 
os autores que devem ser criticados" (Schlegel 19, XVIII, p. 126). O "pôr" a que esta passagem se refere é um referência ao ato do crítico que deve pôr a obra diante do seu próprio Ideal. Ou seja, para os românticos - do mesmo modo como ao poeta cabia a tarefa de recriar a linguagem, que era vista como insuficiente - nesta crítica divinatória as obras são vistas como realizações incompletas - abertas - de um Ideal e devem ser aproximadas dele no ato da crítica. "Apenas o incompleto pode ser compreendido, pode levar-nos mais além", afirmou Novalis (14, II, p. 348). E Schlegel: "Toda crítica é divinatória, completar um projeto é idêntico a completar um fragmento" (Schlegel 19, XVIII, p. 49). Daí porque para ele: "O verdadeiro crítico é um autor elevado à segunda potência" (id., ibidem, p. 106); ou então: "Toda crítica é potenciada. (...) Só existe crítica onde o absoluto e o empírico são sintetizados" (id., 20, 622 ; cf. Benjamin 1, I, p. 69 e segs.) O crítico intervém portanto naquele trabalho de romantização do mundo, de conexão entre o real e o Ideal; o seu mote é a construção do livro único, da enciclopédia ou Bíblia, que como modalidades do "Livro absoluto" estavam no centro da filosofia romântica da linguagem (Seligmann-Silva 22, pp. 48-68). Como afirmou Schlegel, para o crítico: "Toda escrita deve tornar-se sagrada" (Schlegel 19, XVIII, p. 212). A crítica é que transforma o texto em escrita sagrada, isto é, em termos mais profanos, conecta cada obra ao seu próprio Ideal.

Neste ponto, percebemos na teoria romântica o tempo como concretização tendencial e infinita do absoluto. A definição do Ideal, portanto, é feita por uma crítica divinatória, isto é, que descreve a obra a vir. "Uma definição da poesia só pode determinar o que ela deve tornar-se", como afirmou Schlegel nos fragmentos do Athenäum (19, II, p. 181). Novalis formulou algo semelhante num fragmento de 1798: "uma Idéia não se deixa apanhar numa sentença. (...) A lei do seu progresso deixa-se, no entanto, compor - é a partir dela que o romance deve ser criticado" (Novalis 14, II, 359). O famoso fragmento 116 de Friedrich Schlegel, também do Athenäum, executa justamente esta crítica divinatória - só que aí não de um texto, mas sim da história da literatura vista como um Livro único - , na medida em que define a poesia romântica como uma "tendência", realização de um "projeto": "A poesia romântica está ainda em devir; sim, esta é a sua essência própria, que ela eternamente apenas torne-se e nunca poderá ser completa. Ela não pode ser esgotada por nenhuma 
Seligmann-Silva, M., discurso (20), 1993: 115-136

teoria e apenas uma crítica divinatória poderia ousar querer caracterizar o seu Ideal" (Schlegel 19, II, p. 183). Mas, como já havíamos apenas indicado acima, a crítica não visa um Ideal único que abarque a todas obras singulares; cada obra possui o seu Ideal: "Toda obra possui o seu Ideal a priori - possui uma necessidade em si de estar aî", afirmou Novalis (14, II, p. 421) nesta passagem tantas vezes citada por Benjamin (1, I, pp. 76, 233; II, pp. 105, 238). E Schlegel anotou: "A crítica compara a obra com o seu próprio Ideal" (Schlegel 20, 1135). E ainda: "Deve poder existir um número infinito de Bíblias" (id., 19, XVIII, p. 236), escreveu Schlegel, revelando o caráter eminentemente conceitual da sua noção de Bíblia.

Mas não é apenas em termos de cada obra que se dá a pluralidade de Idéias. Assim como a noção romântica de verdade envolvia uma ligação entre o absoluto e a sua irrupção - fragmentada, witzig — no tempo e no espaço (Seligmann-Silva 22, pp.69-91), o mesmo se dá com a crítica que se vincula deste modo à teoria da leitura produtiva ${ }^{(8)}$. As obras possuem não apenas o seu próprio Ideal, mas também este Ideal varia conforme o leitor-crítico de cada obra. "Toda obra", afirmou Novalis, "não interessando se, como tal, foi escrita com ou sem intenção, [...] pode ser julgada de um modo tão plural — como o próprio homem" (Novalis 14, II, p. 391). Ou ainda, segundo Schlegel: "Será que é possível (...) abarcar o espírito inteiro de um escrito? Se existe algum, ele é infinito" (Schlegel 19, XVIII, p. 115). Ora, se a Idéia ou Ideal é uma entidade individual e se, por outro lado, mesmo esta Idéia individual é passível de várias leituras, qual o significado desta categoria romântica?

Benjamin, com a sua concepção de arte como medium-de-reflexão "sua", porque é ele quem explica o conceito romântico de crítica da época do Athenäum com esta categoria — , foi sem dúvida o autor que melhor soube responder a esta questão: "o conceito de crítica de Schlegel não conquistou apenas a liberdade com relação às doutrinas estéticas heterônimas — antes, ele possibilitou isso, apenas pelo fato de ter posto um outro critério de obra de arte que não a regra: o critério de uma determinada construção imanente, da própria obra. Ele o fez [...] com uma [...] teoria própria da arte: como um medium-dereflexão, e da obra: como um centro da reflexão. Desta maneira, ele assegurou do lado do objeto ou da conformação aquela autonomia no campo da arte que Kant havia conferido ao juízo na crítica do mesmo" (Benjamin 1, I, pp. 71 e 
segs.). Esta concepção da crítica baseada na "construção imanente" de cada obra tem como centro uma teoria da forma. A forma expõe, para os românticos de Jena, a reflexão da obra. Benjamin reconstrói o conceito romântico de crítica de arte a partir desta noção: "A crítica preenche a sua tarefa", afirmou ele, "na medida em que ela, quanto mais cerrada for a sua reflexão, quanto mais rígida a forma da obra, quanto mais multiplamente e intensivamente leve estas [a reflexão e a forma] fora de si, dissolva a reflexão originária numa superior e assim por diante. Neste trabalho, ela apóia-se nas células germinais da reflexão, nos momentos positivamente formais da obra, que ela dissolve em momentos universalmente formais. "Assim", conclui o autor, "ela expõe a ligação da obra única com a Idéia da arte e, deste modo, a Idéia mesma da obra singular" (Benjamin 1, I, p. 73). O trabalho de potenciação que a crítica realiza consiste, portanto, repetindo, no desdobramento da reflexão formal contida em cada obra, elevando estes elementos germinais à Idéia da obra e à Idéia da arte. Benjamin ressalta que a Idéia da arte é, para os românticos, na verdade, igual ao medium-de-reflexão das formas, isto é, é através da conexão da construção imanente de cada obra com o seu próprio potencial formal (ou Ideal individual) e, por outro lado, com a ligação deste com o continuum das Formas, que se funda a noção de unidade da poesia do romantismo (Benjamin 1, I, p. 87), que não é nada mais do que a Idéia da arte realizada no tempo.

Mas não é apenas a crítica que realiza este trabalho de conexão entre as obras e as Idéias. Internamente, a própria obra o realiza através da ironia formal. Vale a pena citarmos os termos com que Benjamin expõe este ponto, pois ele retomou mais tarde esta teoria dentro da sua própria filosofia da arte: "A forma determinada da obra singular, que se poderia designar como formade-exposição [Darstellungsform], torna-se a vítima da destruição irônica. Sobre ela, no entanto, a ironia rasga um céu de forma eterna, a Idéia das formas, a que se poderia denominar de forma absoluta, e esta atesta a sobrevida da obra que extrai desta esfera a sua existência indestrutível, depois que a forma empírica, a expressão da sua reflexão isolada, tenha sido consumida por ela" (Benjamin 1, I, p. 86). Benjamin destaca então a dificuldade, por parte de Schlegel, de conseguir equilibrar na sua teoria o papel das obras individuais e o da Idéia da arte. Também esta passagem da sua tese deve ser citada: "Para expressar a individualidade da unidade da arte, Schlegel estendeu por demais 
os seus conceitos e lançou mão de um paradoxo. De outro modo teria permanecido irrealizável a idéia de expressar a mais elevada universalidade como individualidade. Esta idéia não possui, por sua vez, como motivo último uma absurdidade ou mesmo apenas um erro; antes, Schlegel meramente interpretou nela de maneira errada um motivo importante e válido. Este motivo consistia no esforço de preservar o conceito de Idéia da arte do mal-entendido segundo o qual ele seria uma abstração das obras de arte empiricamente dadas. Ele queria determinar este conceito como uma Idéia no sentido platônico, como um próteron té physei, como uma base real de todas obras empíricas, e ele iniciou a antiga confusão entre o abstrato e o universal quando acreditou que se devia, para tanto, fazer um conceito individual. Apenas com este propósito Schlegel indicou repetidas vezes e com ênfase a unidade da arte, o continuum mesmo das formas como uma obra. Esta obra invisível é aquela que acolhe em si a obra visível" (Benjamin 1, I, pp. 89 e segs.) ${ }^{(9)}$. Esta aparente desproporção, no entanto, entre a Idéia - continuum das formas, a obra invisível - e as obras visíveis, individuais, Schlegel procura constantemente relativizar e mostrar ainda nas palavras de Benjamin — que "a Idéia é obra e também, se esta vence a limitação da sua forma-de-expressão, a obra é Idéia" (Benjamin 1, I, p. 91). Está claro, portanto, que a teoria das Idéias de F. Schlegel está longe de ser um platonismo puro, uma doutrina do mundo das Formas como causa do mundo material, mas antes envolve a tentativa "paradoxal" de conectar — dentro do esquema infinito da reflexão da obra e da sua exposição através da crítica por um lado, as conformações artísticas individuais às suas próprias Idéias singulares e, por outro, estas à Idéia da arte.

A teoria das formas ou gêneros poéticos é, consequentemente, central dentro da filosofia romântica da arte. Esta tensão apontada por Benjamin entre a valorização da Idéia da arte e a da obra individual gerou, na bibliografia secundária sobre o romantismo, opiniōes díspares quanto a este ponto ${ }^{(10)}$. Como o fragmento 434 do Athenäum deixou claro, primeiro que tudo $\mathrm{F}$. Schlegel visou a uma crítica das concepções tradicionais de gênero: "As divisões habituais da poesia são apenas madeiramento morto para um horizonte limitado" (Schlegel 19, II, p. 252). A continuação deste fragmento dá conta novamente de que a única tarefa que se pode realizar é uma tentativa de se perceber a "tendência" da poesia. A crítica da razão da poética dos gêneros 
levada a cabo por Schlegel - na expressão de Peter Szondi ("Kritik der gattungspoetischen Vernunft") — deu-se através de um processo de utilização dos mesmos apenas como "tons" que marcariam as diversas obras poéticas e misturar-se-iam nelas (Szondi 24, pp. 192 e segs.) ${ }^{(11)}$. Evidentemente a base para tal superação dos gêneros está dada na modernidade, para este autor, através do romance - ou da poesia romântica — que, como "forma progressiva"(12), engloba potencialmente todos estes gêneros que são superados e misturados nela. "Todos os tipos de poesia [Dichtarten] clássicos, na sua pureza estrita, são agora risíveis" , afirmou ele (Schlegel 20, II, p. 154) em 1797, e no mesmo ano ainda: "Sentido para a individualidade poética tem-se apenas com os modernos" (Schlegel 20,199). Como complemento a esta idéia, veja-se esta outra passagem: "Pode-se tanto dizer que existem tantos infinitos tipos de poesia ou que só existe um tipo progressivo. Portanto não existe nenhum" (Schlegel 20,583). Assim como os românticos afirmaram existir uma Idéia para cada obra, do mesmo modo, portanto, Friedrich Schlegel pôde escrever em 1798: "Cada obra um gênero [Gattung] para si" (Schlegel 20, 1090). Esta teoria dos gêneros — ou melhor dizendo, desconstrução da teoria tradicional dos gêneros - , como a leitura dos fragmentos sobre literatura de Friedrich Schlegel deixa claro, implica a realização do programa exposto no Gespräch über die Poesie: "decerto o que nos falta é precisamente uma teoria dos tipos de poesia. E que outra coisa poderia ela ser senão uma classificação, que fosse ao mesmo tempo história e teoria da arte da poesia?" (Schlegel 19, p. $305)^{(13)}$.

Novalis, por sua vez, tratou de levar ao paroxismo a valorização da poesia enquanto espera insondável, esotérica, não-conceitual e, portanto, não passível de ser submetida a qualquer classificação. Coerentemente com a sua teoria da insuficiência e pobreza da nossa linguagem cotidiana prosaica, ele afirma a impossibilidade do discurso sobre a poesia: "A poesia é totalmente pessoal e, deste modo, indescritível e indefinível. Quem não sente e sabe, imediatamente, o que a poesia é, não pode introduzir nenhum conceito dela. Poesia é poesia. Incomensuravelmente diversa da arte-do-discurso(-linguagem) [Rede(Sprach)kunst]" (Novalis 14, II, p. 839. E: "Crítica da poesia é absurdo. Já é difícil de se decidir, decerto a única decisão possível, se algo é poesia ou não" (Novalis 14, II, p. 840). Mas, evidentemente, o próprio Novalis, 
Seligmann-Silva, M., discurso (20), 1993: 115-136

com os seus inúmeros fragmentos sobre a literatura - Goethe e Shakespeare sobretudo - , praticou a crítica no sentido romântico do termo. De resto, como em outros textos, nos seus Treplitzer Fragmente, este mesmo autor teorizou esta crítica, afirmando: "Ela é em parte filosófica, em parte histórica - aquela é a sua parte mais pura - esta a sua parte aplicada" (Novalis 14, II, p. 388).

A consequêencia desta constelação de idéias sobre a filosofia da arte desaguou naturalmente numa teoria da crítica poética, ou seja, apenas através de uma linguagem poética - mais próxima da linguagem originária do texto literário - é que pode-se dar, para os românticos, o discurso sobre a poesia (Novalis 14, I, pp. 69 e segs). "Quem não pode fazer poesia alguma, também vai julgá-la apenas de modo negativo. À autêntica crítica pertence a capacidade de gerar o produto que é criticado. O gosto sozinho julga apenas negativamente"; "Compreende-se o artista, apenas na medida em que se é artista e torna-se tal e que se compreende a si mesmo", afirmou Novalis (14, II, p. 323 e p. 690). F. Schlegel também compartilhou desta convicção de Novalis, como ele deixou claro em várias passagens e fragmentos: "A poesia só pode ser criticada pela poesia. Um juízo artístico que não seja, ele próprio, uma obra de arte, quer na matéria, enquanto exposição da impressão necessária no seu devir, quer através de uma bela forma e com um tom liberal no espírito da antiga sátira romana, não possui nenhum direito de cidadania no reino da arte" (Schlegel 19, II, p. 162). E nas Ideen: "Quem quebrará o selo do livro mágico da arte e libertará o espírito sagrado aí encerrado? - Apenas o espírito aparentado" (Schlegel 19, II, p. 271). ${ }^{(14)}$ Este princípio que acarreta uma total supressão dos limites entre a reflexão crítica e a ficção baseava-se, na verdade, na doutrina romântica das analogias, como este último fragmento deixa transparecer. Como destacou Benjamin, para os românticos valia a máxima: "cada essência conhece apenas aquilo que é igual a ela mesma e só pode ser conhecida através de essências que são iguais a ela. Com isto toca-se na relação entre sujeito e objeto do conhecimento, que, segundo a concepção romântica, não desempenha nenhum papel com relação ao autoconhecimento" (Benjamin 1, I, p. 56). (15)

Esta noção está relacionada àquela outra também já exposta aqui segundo a qual nós conhecemos apenas a auto-reflexão do próprio objeto sobre o qual nos debruçamos. Este princípio também é aplicado à crítica de obras literárias. F. Schlegel, na sua crítica do Meister de Goethe, reafirma este aspecto da 
crítica romântica ao falar desta obra como um livro "que se pode compreender apenas a partir de si mesmo" - isto é, a crítica deve proceder com relação a ele por via de uma análise interna da obra - e ainda: "Felizmente este é justamente um destes livros que se julgam a si mesmos, e que deste modo dispensam o esforço do juiz da arte [Kunstrichter]. Na verdade, ele não apenas julga a si mesmo, como também expõe-se a si mesmo" (Schlegel 19, II, pp. 133 e segs.). Portanto, assim como a crítica deve ser poética, do mesmo modo a obra de arte também é ela mesma crítica: "Na poesia romântica, a crítica romântica deveria estar conectada com a poesia mesma; assim elas serão potenciadas" (Schlegel 20,792). Novalis também expressou algo semelhante ao afirmar: "A resenha [Recension] é complemento do livro. Alguns livros não carecem de resenha — apenas de um anúncio - Eles já trazem a resenha neles" (Schlegel 19, II, p. 605).

Este princípio romântico estava ligado a um pressuposto teórico: "Tudo o que não se auto-aniquila não é livre e não tem valor" (Schlegel 19, XVIII, p. 82). Apenas as obras não-heterônomas que contenham este movimento crítico interno, segundo os românticos, merecem e podem ser criticadas; ou seja, podem ter a sua auto-reflexão exposta. O conceito de crítica derivado destes pressupostos é inteiramente positivo. "Apenas o clássico e o progressivo merecem ser criticados" (Schlegel 20,125); "Que não se deveriam julgar obras ruins, é uma certeza", afirmou Schlegel $(20,71)$, entre outros fragmentos sobre este mesmo tema. Na sua conclusão de 1801 do artigo sobre Lessing ele escreveu: "a verdadeira crítica não toma nota das obras que não contribuam para o desenvolvimento da arte e da ciência; decerto, por conseguinte, não é possível uma crítica do que não esteja vinculado com aquele organismo da formação [Bildung] do gênio, do que simplesmente não existe para o todo e no todo" (Schlegel 19, I, p.411).(16)

Esta conexão que deve existir com o todo, no sentido mais amplo desta palavra, que Schlegel reivindicou como uma das marcas da crítica, também foi manifestada, em âmbitos mais restritos, quando ele falou da exigência de se conhecer a obra inteira do autor, para se poder julgar cada texto individual. Com relação àquele círculo mais amplo, Schlegel pôde afirmar sua convicção da unidade das obras de arte: "A essência da alta arte e forma consiste na relação com o todo. Devido a isso elas são incondicionalmente finalidades 
[zweckmässig] e incondicionalmente sem finalidade [zwecklos], devido a isso elas são tidas pelo que há de mais sagrado e amadas infinitamente uma vez conhecidas. Devido a isso todas obras são uma obra, todas artes uma arte, todas poesias uma poesia" (Schlegel 19, II, p. 414). Cada obra, portanto, deve ser sempre observada historicamente, dentro do "âmbito da história da arte [...] do todo maior" (Schlegel 19, II, p. 391); daí o porquê de Schlegel ter procurado ver a "crítica como síntese da filosofia, poesia e história" (Schlegel 20, 649)(17). Já no Versuch über den verschiedenen Styl in Goethes früheren und späteren Werken Schlegel expôs de modo cristalino o que ele compreendia pelo importante princípio hermenêutico da relação das partes com o todo no processo de compreensão de um texto: "O poeta pode seguir o seu gosto próprio e mesmo para o amante isso pode ocorrer por algum tempo: mas o conhecedor, e aquele que quer atingir o conhecimento, deve esforçar-se para conhecer o poeta mesmo, isto é, tanto quanto isto seja possível, esquadrinhar a história do seu espírito. Isso pode quedar apenas como uma tentativa, pois na história da arte um complexo é esclarecido e iluminado apenas por um outro. Não é possível conhecer-se uma parte nela mesma" (Schlegel 19, II, p. 340). Schlegel referese ainda ao círculo hermenêutico entre as partes e o todo dentro da análise de cada obra particular: "Que na obra de arte não se deveria sentir simplesmente os locais belos, mas abarcar a impressão do todo; esta proposição torna-se logo trivial e fará parte dos artigos de fé", afirmou ele (19, II, p. 410) em $1801^{(18)}$.

Com relação ao Über Goethes Meister de Schlegel, deveríamos ainda apenas destacar dois pontos: em primeiro lugar, a sua análise alegórica dos personagens da obra, que B. Witte salientou na sua tese sobre Benjamin e que A. Berman notou que se pode considerar como mais uma das formas de os românticos atuarem na descontrução do elemento referencial das obras literárias (Witte 28; Berman 2, p. 144: cf. Schlegel 19, II, p. 143). Em segundo lugar devemos ressaltar o tratamento que Schlegel deu à análise formal da obra. Ele acentuou o caráter eminentemente lúdico e mesmo musical que Goethe teria dado à construção do todo da obra através da montagem das suas partes (Schlegel 19, II, pp. 128 e segs.: Menninghaus 13, p. 174 passim).

Um teórico atual da literatura teria notado decerto a ausência de um elemento importante nesta descrição do conceito romântico de crítica de arte: o público. Os românticos teorizaram a situação do público especializado, do 
crítico da obra diante da tarefa de ter que desenvolver um discurso sobre ela sem poder mais se apoiar num esquema de leis objetivas dado pela tradição. Já o público em geral, eles na verdade teorizaram indicando qual seria o local de tal categoria dentro da crítica romântica: "Muitos falam de tal modo do público, como se ele fosse alguém com quem se tivesse almoçado na feira de Leipzig, no Hotel de Saxe [...] O público não é, de modo algum, uma coisa, mas sim um pensamento, um postulado como a Igreja" (Schlegel 19, II, p. 150), afirmou ironicamente Schlegel em 1797. Esta crítica da categoria público deve ser ligada à própria concepção esotérica de poesia como um medium e não como um meio de se expressar uma dada mensagem. Num fragmento deste mesmo ano, Schlegel diferenciou o autor analítico que visa gerar um determinado efeito no leitor, do sintético que escreve com um leitor ideal em mente, sem pensar em efeito algum sobre os leitores (Schlegel 19, II, p. 161). Ele criticou reiteradas vezes a estreiteza de horizonte do público da sua época, o que representa, portanto, não um desprezo por este elemento essencial a qualquer teoria literária, mas antes uma crítica tanto a uma visão hipostasiada desta categoria enquanto tal, como também a uma eventual tomada do "gosto médio" do público como padrão para guiar a produção literária. Mesmo a crítica literária não deveria ser submetida a tal limite: "Aqueles que escrevem livros e depois pensam que os seus leitores são o público e que eles deveriam formar este público: estes logo vêm não apenas a desprezar o seu público, mas a detestá-lo; o que não pode levar a nada" (Schlegel 19, II, pp. 155 e segs.). E: "O objetivo da crítica, diz-se, é o de formar leitores! - Quem quer ser formado, deve pois formar-se a si mesmo. Isto é descortês: mas não pode ser modificado" (id., 19, II, p. 157). Evidentemente tal postura só poderia conduzir Schlegel a uma valorização de um "público" limitado de iniciados para a literatura, ou seja, a uma valorização do círculo de leitores especializados; numa atitude, diga-se de passagem, "vanguardista": "Eles lamentam-se sempre que os autores alemães escrevem apenas para um círculo pequeno, até mesmo, frequentemente, apenas uns para os outros. Isto está certo. Assim a literatura alemã irá sempre receber mais espírito e caráter. E, entrementes, pode ser que surja um público" (id., 19, II, p. 212).

Benjamin concluiu a sua tese sobre o conceito de crítica romântica criticando a postura de Goethe que não via o "ser criticável" da obra [die Kritisier- 
Seligmann-Silva, M., discurso (20), 1993: 115-136

barkeit] como um elemento central na obra de arte e também ressaltando, por outro lado, o paradoxo diante do qual encontrava-se o conceito romântico de crítica: o de valer mais do que a própria obra de arte (Benjamin 1, I, p. 119). Assim como o crítico é o autor elevado à potência, para os primeiros românticos também a crítica é a elevação da obra à sua potência, a intensificação e exposição da sua reflexão (e também da do sujeito, do crítico) ${ }^{(19)}$ — do mesmo modo como a tradução também ultrapassava, como vimos, para estes autores, a obra "original" - construindo assim a teoria de uma "crítica contra Babel", se nos for concedido assim alterar a expressão de A. Berman ${ }^{(20)}$. A crítica, portanto, incumbe-se da tarefa de construir, de criar a obra infinita, absoluta, de reescrever o "Livro do Mundo" cuja chave de acesso - como escreveu Novalis - está perdida; ela não ultrapassa a poesia mas é ela mesma poesia assim como a poesia já é ela mesma crítica.

Não é, portanto, desprovido de interesse se Peter Szondi, no seu ensaio sobre a teoria schlegeliana dos gêneros, tenha posto em evidência o fato de que, após a obra deste autor romântico, aquela teoria tenha encontrado o seu auge e fim na estética de Hegel, que, no seu sistema, solucionou a questão da relação do particular com o universal: "Indução e dedução", afirmou Szondi (24, p. 187), "são mediatizados, em Hegel, porque os conceitos são dados não como algo para além do empírico, mas sim são postos como atingindo a eles mesmos no empírico, na história". Como o mesmo autor ainda notou com razão: a poética de Hegel "só pode ser ultrapassada na medida em que se volte para trás dela. Portanto (...) não foi feito nada de novo na poética dos gêneros [Gattungspoetik] na linhagem do sistemático Hegel, mas antes recorrendo-se à concepção do romantismo da filosofia da história na sua conexão com os gêneros poéticos. É testemunha disto", conclui Szondi, "o Ursprung des deutschen Trauerspiels de Benjamin e a Theorie des Romans de Lukács de dez anos antes. Lukács assim como Benjamin, redigiram os seus escritos com base numa relação intensa com Friedrich Schlegel" (id., ibidem). Ora, essa "volta a F. Schlegel — e a Novalis" — não se deu para Benjamin apenas no âmbito da teoria dos gêneros, mas sim com o todo da obra romântica. O Benjamin romântico, no entanto, foi "descoberto" como tal pelos seus "especialistas" apenas na década de oitenta: "coincidentemente" junto com a difusão da teoria da pós-modernidade. Alguns expoentes desta recepção da obra de Benjamin 
são Christine Buci-Glucksmann (4), Winfried Menninghaus e Philippe LacoueLabarthe, que compilou juntamente com Jean-Luc Nancy uma obra de tradução e comentário de textos do primeiro romantismo alemão que teve grande repercussão (Lacoue-Labarthe/Nancy, 12). Nela os autores reiteradas vezes conectam o romantismo de Jena à obra de Derrida e (à pós-modernidade). O resultado deste círculo de influências é sintomático: Menninghaus parte da obra de Benjamin para resgatar um primeiro romantismo carregado de tinturas pós-estruturalistas ${ }^{(21)}$; Buci-Glucksmann traça uma linha do barroco a Derrida, passando pelo primeiro romantismo, por Baudelaire e Benjamin; Lacoue-Labarthe e Nancy vão sistematizar a teoria literária do romantismo alemão com um instrumental teórico desenvolvido no bojo do pós-estruturalismo - Derrida e da tese de Benjamin sobre os primeiros românticos. Recordando a dialética do limite benjaminiana (hegeliana?), poder-se-ia então concluir: F. Schlegel e Novalis não apenas se encontram entre os fundadores da modernidade, mas, no ato mesmo da sua fundação, superaram-na. ${ }^{(22)}$

Abstract: This article discusses F. Schlegel's and Novalis notion of criticism. Since the german romanticism it is not possible to speak about "art" without the self-reflection. But on the other hand the "critique", the self-reflecting activity must become "artistical" too.

Keywords: german romanticism - art - criticism - german idealism.

\section{Notas}

(1) O drama burguês representava uma ação trágica num meio vulgar, o que invertia as máximas de Aristóteles, que na sua Poética vinculara a tragédia às ações superiores e a comédia às ações inferiores. Cf. Genette (9).

(2) Além disso, Kant elevou com a sua terceira crítica o âmbito estético à categoria de intermediador entre a razão e o entendimento, entre a liberdade e a necessidade, idéia esta que teve um impacto singular na filosofia romântica, o que, aliás, pode ser compreendido facilmente se tivermos em mente a diferenciação elaborada por Kant, 
na introdução desta sua obra, entre os juizos determinantes (que procedem subsumindo o particular a uma regra ou lei geral) e os reflexionantes (o teleológico e o estético, que partem do singular na direção da universalidade). Com relação ao impacto que esta obra de Kant teve no jovem F. Schlegel, cf. Eichner (5, p. 20).

(3) Quanto a este ponto è à poética de Chlaudenius e Meier, dois dos maiores representantes desta linha, cf. Szondi 23, passim.

(4) Cf. ainda Hans Robert Jauss (11, pp. 67-106), que ressaltou o importante papel que a leitura do estudo de Schiller Über naive und sentimentalische Dichtung desempenhou nessa nova atitude positiva de $F$. Schlegel diante da poesia moderna. Para uma postura oposta - isto é, que vê nos textos de 1795 de Schlegel já um embrião da teoria romântica da literatura —, cf Brinkmann (3, pp. 344-347).

(5) Cf. também: "Os críticos falam sempre de regras, mas onde estão as regras verdadeiramente poéticas e não apenas gramáticas, métricas, lógicas ou válidas para todas as obras" (Schlegel 19, II, p. 286).

(6) Vale ressaltar, no entanto, que esta teoria da genialidade do artista não tem nada a ver com uma apologia da produção inspirada ou com a teoria do gênio do Sturm und Drang. Cf. Benjamin (1, I, pp. 52 e segs.) e Berman (2, p. 126).

(7) $R$. Wellek notou também a importância dessa concepção para a teoria de August Wilhelm Schlegel: "So kann man auch ein Gedicht oder sonst ein Kunstwerk mit recht idealisch nennen", afirmou A. Schlegel, "wenn sich in ihm [...] Buchstabe und Geist bis zur völligen Ununterscheidbarkeit gegenseitig durchdrungen haben." (Wellek 26, p. 315) Walter Benjamin expressou uma ordem de idéias muito semelhante no seu ensaio Goethes Wahlverwandtschaften, (I, I, pp. 123-201).

(8) Isto é, ao ato de leitura como parte integrante da confeç̧ão da obra: "O verdadeiro leitor deve ser o autor prolongado" , afirmou Novalis (14, II, p. 282), e Schlegel (19, XVIII, p. 252): "Apenas o leitor faz da Bíblia, Bíblia"

(9) A relação entre esta passagem e a teoria da arte do próprio W. Benjamin, sobretudo tal como ele a expôs no prefácio do seu livro sobre A Origem do Drama Barroco Alemão - articulando as suas noções de obra, conceito e Idéia platônica - é clara a qualquer leitor mais atento dessa obra. 
(10) Todorov $(25, p .193)$ ressalta esta ambigïidade afirmando que F. Schlegel "por um lado [...] reconhece as coaçōes exercidas pela forma literária sobre a obra individual; por outro lado, no entanto, aprecia a diferença irredutível de cada obra, anunciando assim a atitude extrema de Croce". Eichner afirma algo semelhante ao dizer que em F. Schlegel "assim como Benedetto Croce o preconizará cerca de cem anos depois - cada obra é observada como sui generis, como única, de tal modo que nenhuma lei abstraida de outra obra de arte pode lhe servir" (Eichner 5, p. 21). Já $R$. Wellek (26, p. 45) notou com relação a A.W. Schlegel que "o conceito da unidade completamente auto-suficiente de uma obra de arte conduz ao conceito de sua absoluta 'singularidade' e, em Croce e outros modernos, à conseqüência lógica de rejeitar-se inteiramente o conceito de gênero. Tal não acontece com Schlegel, que mantém com firmeza a metáfora biológica, a qual sugeriria que cada indivíduo, embora indivíduo, também pertence a uma espécie."

(11) Schlegel, na medida em que tratou a epopéia, a lírica, o drama como tons ou modos, aplicáveis aos diferentes gêneros (romance, sátira, idilio, balada, conto, fábula ...), marcou a superação da concepção dos gêneros como entidades estanques, hipostasiadas.

(12) Aliás, não propriamente "forma", mas sim "elemento da poesia", como fez questão de ressaltar $F$. Schlegel no seu Brief über den Roman (19, II, p. 335).

(13) No fragmento 322 dos Fragmente żur Literatur und Poesie, Schlegel (19, p. 322) ressalta que a reflexão sobre a forma da obra é o meio de ligá-la ao continuum das obras; a forma representaria, portanto, o elemento trans-histórico destas, sendo que o conteúdo seria totalmente determinado pela época. Cf. P. Szondi $(24, p .194)$. Como A.. Berman (2, pp. 143 e segs.), de modo pertinente, também destacou, havia uma dependência total entre as teorias românticas da obra de arte e da linguagem e, portanto, assim como o poeta deveria visar à linguagem não-referencial, do mesmo modo ele, através da ironia, da reflexão e do tropos, deveria executar uma supervalorização da forma da obra de arte em detrimento do seu conteúdo.

(14) Cf. ainda Schlegel (19, II, p. 258 e p. 337), onde se lê que uma teoria do romance deveria dar-se no sentido etimológico do termo "teoria", ou seja, como visão espiritual do objeto: "Uma tal teoria do romance" - concluiu Schlegel "teria de ser ela mesma um romance." O seu romance Lucinde pode ser lido justamente como uma 
realização de tal programa. No número 808 dos seus Fragmente I (20, 808), ele escreveu: "Imperativo do absolumente romântico: A poesia crítica deve ser poética".

(15) Novalis, por exemplo, escreveu: "Assim como o olho só vê olho - assim o entendimento apenas entendimento - a alma, almas - a razão - razão - o espírito - espíritos etc. A imaginação apenas imaginação - os sentidos - sentidos. Deus só vem a ser conhecido através de um Deus etc." (Novalis 14, II, p. 700). Este tema era constante nas ciências naturais da época e foi também tratado por Goethe na sua Farbenlehre e por Fichte, que ,na sua Grundlage der gesammten Wissenschaftslehre, afirmou que "a imaginação só pode ser abarcada pela imaginação" (Fichte 6, p. 284).

(16) F. Schlegel afirmou também a importância da polêmica no trabalho de separar os objetos dignos de ser criticados daqueles que não o são. Ele deixou, no entanto, claro o caráter inferior da polêmica - "A polêmica é [...] serva da crítica" (19, XVIII, p. 107) - chegando inclusive a estabelecer uma diferenciação em termos de vincular a polêmica à filologia e a crítica à filosofia: "A filologia é mais polêmica, a filosofia mais crítica"; e ainda: "A crítica abre-se ao espírito, a polêmica à letra" (19, XVIII, p. 113), o que reforça a concepção da filologia como 'trabalho sobre o espirito'das obras - reflexão sobre e no continuum das formas.

(17) Cf. o seguinte interessante fragmento de 1798 de $F$. Schlegel que revela a importância do local ocupado pela história na sua obra: "Kritik und Politik die Faktoren der Historie. Ich für Historie, was Goethe und Fichte für Poesie und Philosophie" (Schlegel, 20, 2107).

(18) Cf. ainda o seu "Georg Forster" de 1797, onde ele já afirmara esta mesma idéia (Schlegel 19, II, p. 84). Devido a concepções como estas, F. Schlegel deve ser visto como o pai da hermenêutica moderna, que foi logo em seguida sistematizada pelo seu amigo $F$. Schleiermacher que teorizou, por sua vez, o círculo hermenêtico nos seus fragmentos de 1805-10 onde, entre outros, podemos ler: "Toda compreensão do individual é condicionada pela compreensão do todo" (Schleiermacher, 21, p. 46). Schleiermacher diferenciou dois tipos de abordagem do texto: a interpretação gramatical e a técnica. A primeira ele subdividiu na análise sintagmática (análise interna do discurso - "Rede") e paradigmática. Nesta última o hermeneuta deveria analisar a relação do discurso com a tradição, com a cultura. Este todo, "das Ganze", com o qual o discurso individual deve ser confrontado inclui também uma teoria dos gêneros. Esta abordagem encontrava-se, portanto, ao menos in nuce, já 
na obra de F. Schlegel. Schleiermacher evidentemente não apenas desenvolveu a hermenêutica enquanto arte (téchne) de interpretação, como desenvolveu a interpre. tação técnica, preocupada com o estudo da gênese do discurso e com o importante tema do estilo. Quanto ao papel da obra de F. Schlegel na fundação da hermenêutica literária cf. o ensaio de Hermann Patsch (15).

(19) Benjamin, na sua tese, privilegiou a exposição da reflexão da própria obra, mas os românticos acentuaram o caráter recíproco deste movimento de "desdobramento infinito" tanto da obra quanto do sujeito, isto é, a obra é desdobrada apenas num processo histórico de atualização, é apenas através da sua exposição que ela atinge a sua Idéia e a Idéia da arte, ou seja o continuum das formas.

(20) Na sua obra sobre a teoria romântica da tradução, Berman (2, p. 21) a descreve nos termos de uma "traduction contre Babel". Cf. Seligmann-Silva 22, p. 187.

(21) Vale notar que na Alemanha, sobretudo devido à influente obra de Manfred Frank (7), - que foi um dos principais introdutores de Derrida e Lyotard na teoria literária e filosofia alemãs -, "pós-modernidade" e "pós (ou neo-) estruturalismo" são dois conceitos muito interligados.

(22) A mais recente tentativa de ver a obra de Benjamin como "Biblia" (!) da pós-modernidade e ainda dentro desta conexão com os românticos de Jena particularmente com os seus conceitos de ironia e fragmento -, pode ser acompanhada num recente lançamento organizado por Willem van Reijen (16), no qual vincula-se — mais uma vez - a teoria benjaminiana da alegoria com a "perda" do significante e do significado transcendentais. 


\section{Bibliografia}

1. Benjamin, W. Gesammelte Schriften. Organização de R. Tiedemann e H. Schweppenhäser. Frankfurt am Main, Suhrkamp, 1974, volumes I e II.

2. Berman, A. L'épreuve de l'étranger; culture et traduction dans l'Allemange romantique. Paris, Gallimard, 1984.

3. Brinkmann, R. Romantische Dichtungstheorie in Friedrich Schlegels Frühschriften und Schillers Begriffe der Naive und Sentimentalischen. In: Deutsche Vierteljahrsschrift für Literaturwissenschaft und Geistesgeschichte, v. 32, 1958, pp. 344-371.

4. Buci-Glucksmann, C. La raison baroque de Baudelaire à Benjamin. Paris, 1984.

5. Eichner, H. Friedrich Schlegels Theorie der Literaturkritik. In: Romantik heute. Bonn/Bad-Goderberg, 1972.

6. Fichte, J. G. Über den Begriff der Wissenschaftslehre oder der sogennanten Philosophie. In: Sämtliche Werke. Leipzig, 1975.

7. Frank, M. Was ist Neostrukturalismus? Frankfurt am Main, Suhrkamp, 1983.

8. Gadamer, G. Wahrheit und Methode. J.C.B Mohr, 1960.

9. Genette, G. Genres, "types", modes. In: Poétique, 32, nov. 1977.

10. Hoffmeister, G. Deutsche und europäische Romantik. Stuttgart, 1978.

11. Jauss, H. R. Schlegẹls und Schillers Replik auf die "Querelle des Anciens et des Modernes". In: Literaturgeschichte als Provokation. Frankfurt am Main, 1970.

12. Lacoue-Labarthe, P./Nancy, J.-L. L'absolut littéraire. Théorie de la littérature du romantisme allemand. Paris, 1978.

13. Menninghaus, W. Unendliche Verdopplung. Die frühromantische Grundlegung der Kunsttheorie im Begriff absoluter Selbstreflexion. Frankfurt am Main, 1987. 
14. Novalis. Werke, Tagebücher und Briefe von Hardenberg. Edição de HansJoachim Mehl e Richard Samuel. Munique/Viena, 1978.

15. Patsch, H. Friedrich Schlegels "Philosophie der Philologie" und Schleiermachers frühe Entwürfe zur Hermeneutik. In: Zeitschrift für Theologie und Kirche, 63, 1966, pp. 434 e segs.

16. Reijen, W. v. Allegorie und Melancholie. Frankfurt am Main, 1992.

17. Rosenfeld, A. O Teatro Épico. São Paulo, 1985.

18. Schlagdenhauffen, A. Die Grundzüge des Athenäums. In: Zeitschrift für deutsche Philologie, v. 88, 1969.

19. Schlegel, F. Kritische Friedrich Schlegel-Ausgabe. Edição de Ernst Behler. Paderborn, 1958.

20. . Literary Notebooks. Edição de Hans Eichner. Londres, 1957.

21. Schleiermacher, F. Hermeneutik. Organização de Heinz Kimmerle. Heidelberg, 1974, $2^{\mathrm{a}}$.

22. Seligmann-Silva, M. Ler o Livro do Mundo: Walter Benjamin - Romantismo e Crítica Poética. Dissertação de mestrado, FFFLCH, 1991.

23. Szondi, P. Einführung in die literarische Hermeneutik. Frankfurt am Main, Suhrkamp, 1975.

24. Friedrich Schlegels Theorie der Dichtarten. Versuch einer Rekonstruktion auf Grund der Fragmente aus dem Nachlass. In: Euphorion, 64, 2, 1970.

25. Todorov, T. Teorias do Símbolo. Tradução de M. Santa Cruz. São Paulo, s.d.

26. Wellek, R. História da Crítica Moderna. São Paulo, Herder-Edusp, 1967, v. 2 .

27. The concept of Romanticism in Literary History. In: Concepts of Criticism. New Haven/Londres, 1963, p. 128-198.

28. Witte, B. Walter Benjamin. Der Intellektuelle als Kritiker. Stuttgart, 1974. 